\title{
Sea surface temperature controls on warm climate water isotopes in Greenland ice cores
}

\author{
Louise C. Sime ${ }^{1}$, V. Masson-Delmotte ${ }^{2}$, C. Risi ${ }^{3}$ and J. Suolte ${ }^{4}$ \\ 'British Antarctic Survey, Cambridge, UK; Isim@bas.ac.uk \\ 2Laboratoire des Sciences du Climat et de l'Environnement, Gif-sur-Yvette, France; ${ }^{2}$ Laboratoire de Météorologie Dynamique, Paris, France; ${ }^{4}$ Lund \\ University, Sweden
}

\section{We present new atmospheric isotope simulations in order to investigate the effect of sea surface temperature changes on the relationship between Greenland surface temperature and water isotopes.}

$R_{t}$ cently, ice core scientists have obtained for the first time a Greenland ice core record covering the entire last interglacial (LIG; Dahl-Jensen this issue; NEEM community members 2013). Previously, ice cores drilled in Greenland have shown that the stable water isotopic value $\left(\delta^{18} \mathrm{O}\right)$ of LIG ice at fixed elevation was enriched relative to present day, with a maximum enrichment across central Greenland regions of at least $+3 \%$ at 126 ka BP (e.g. NorthGRIP Project members 2004). This $+3 \%$ o enrichment has been interpreted as indicating LIG Greenland warmth, but also lower LIG ice sheet topography or warmth outside of Greenland. Thus, achieving a better understanding of the regional drivers of Greenland precipitation $\delta^{18} \mathrm{O}$ is of broad interest to the ice core and wider paleoclimate communities.

\section{LIG forcing versus greenhouse gas driven warming}

In the framework of the Past4Future project, two recent papers have used atmospheric isotope enabled General Circulation Models (GCM) to investigate climatic controls on $\delta^{18} \mathrm{O}$ measured in Greenland ice cores. Each paper has focused on a specific modeling approach.

The first approach uses simulations from the IPSL-CM4 model to simulate the LIG climate using realistic boundary conditions, i.e. 126 ka BP orbital configuration and greenhouse gas (GHG) levels
(Masson-Delmotte et al. 2011). The second approach (also preliminarily investigated in Masson-Delmotte et al. 2011) is as follows: First, two different warm sea surface temperature (SST) scenarios are simulated using the IPSL-CM4 and HadCM3 GCMs forced with high GHG values (see Box 1). Second, the impact of the two SST scenarios on isotopic changes over Greenland is simulated with the respective isotopeenabled atmosphere-only versions of IPSL-CM4 and HadCM3 (Sime et al. 2013). Hereafter, we refer to these three simulations as : (1) IPSL_LIG: IPSL-CM4 LIG simulation driven by $126 \mathrm{ka}$ BP orbital and 126 ka BP GHG forcing; (2) IPSL_A: IPSL-CM4 simulation using present day orbital forcing alongside higher levels of GHG forcing and (3) HadCM3_B: HadCM3 simulation using present day orbital forcing alongside higher levels of GHG forcing (Box 1).

To facilitate simulation inter-comparison, we firstly average the simulated $\delta^{18} \mathrm{O}$ increases over central Greenland (regions above $1300 \mathrm{~m}$ ). We then linearly scale the results so that the three simulations each have a $3 \%$ increase in $\delta^{18} \mathrm{O}$ compared with present day (Fig. 1). This enables a direct comparison between simulated temperature increases over Greenland, and SST changes that could force the observed LIG 3\%o $\delta^{18} \mathrm{O}$ increase. Although observationally based (NorthGRIP Project members 2004), the target of an average of $+3 \%$ in LIG $\delta^{18} \mathrm{O}$ is somewhat arbitrary.
It may not be necessary for the $\delta^{18} \mathrm{O}$ increase to average $3 \%$ across all central regions of Greenland in order to match all interglacial ice core observations. The SST changes simulated within IPSL_A and HadCM3_B also have a degree of arbitrariness, i.e. alternative patterns of SST changes could also drive up Greenland $\delta^{18} \mathrm{O}$ values.

A broad comparison between simulations shows that IPSL_LIG and IPSL_A SST patterns differ where orbitally-dependent seasonal behavior occurs (Fig. 2A-B). However, these differences appear to be smaller than those observed between the purely GHG (orbits as present day) forced IPSL_A and HadCM3_B experiments (Fig. $2 B-C)$.

\section{What surface temperature chang-} es drive a $+3 \%$ increase in $\delta^{18} \mathrm{O}$ ?

For Greenland, above $1300 \mathrm{~m}$, the scaled IPSL_LIG simulation suggests an averaged interglacial surface temperature increase greater than $14^{\circ} \mathrm{C}$. However it also features "cliff-edges" in $\delta^{18} \mathrm{O}$ and surface temperature (Fig. 1A). IPSL_A simulates an interglacial Greenland surface temperature increase of $\sim 10$ to $14^{\circ} \mathrm{C}$ (Fig. 1B) while HadCM3_B simulates an interglacial Greenland surface temperature increase of $\sim 2$ to $8^{\circ} \mathrm{C}$ (Fig. 1C). For the IPSL_A and HadCM3_B simulations, the surface temperature and $\delta^{18} \mathrm{O}$ changes tend to be larger in the northern and central regions

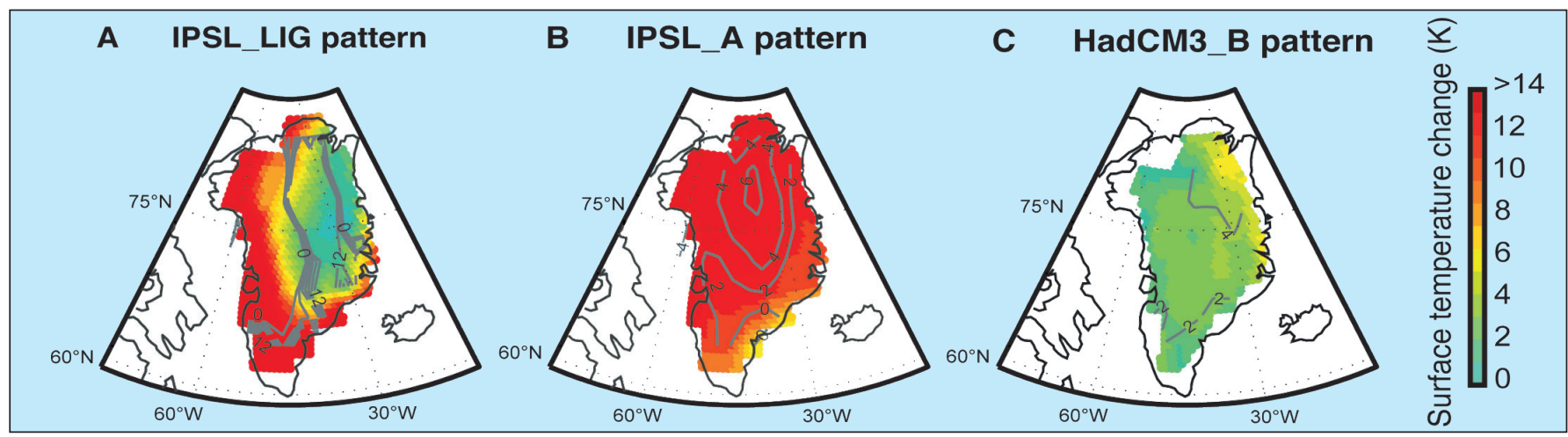

Figure 1: Scaled differences between the control (present day) and the warmer simulations. Climate and isotopic results are scaled such that central Greenland $\delta^{18} \mathrm{O}$ increases by $+3 \%$. A) IPSL_LIG simulation, (B) IPSL_A simulation and (C) HadCM3_B simulation. Shading over Greenland shows the difference between the control and individual simulation values of surface temperature. Contouring shows the difference between the control and individual simulation values of $\delta^{18} \mathrm{O}$. Intervals are $2 \% 0$ and the range is from 0 to $12 \%$. Figure from Sime et al. (submitted) 
Box 1: Orbital forcing configuration and greenhouse gas (GHG) values for the three simulations: IPSL_LIG (Masson-Delmotte et al. 2011) IPSL_A, HadCM3_B (Sime et al. 2013)

\begin{tabular}{l|l|l} 
Simulation & Orbital forcing & \multicolumn{1}{|c}{ GHGs } \\
\hline IPSL_LIG & $126 \mathrm{ka}$ & $126 \mathrm{ka}$ \\
\hline IPSL_A & present-day & $\begin{array}{l}4 \times \text { preindustrial } \\
\mathrm{CO}_{2}\end{array}$ \\
\hline HadCM3_B & present-day & $\begin{array}{l}\text { SRES A1B } \\
2100 \text { scenario }\end{array}$
\end{tabular}

of Greenland compared to present day (Fig. 1B and 1C).

The "cliff-edge" pattern across Greenland from the IPSL_LIG simulation indicates "simulation noise", and scaling to the $+3 \%$ o target requires SST increases that are not within observational bounds (Fig. 2A; McKay et al. 2011; Turney et al. 2010). Thus, despite the appeal of the 126 ka BP simulation (IPSL_LIG) approach, we suggest that climate model dynamics currently prevent an accurate simulation of LIG climate when using realistic orbital and GHG forcing. These model deficiencies could be due to missing physical processes in the ocean, atmosphere, and sea ice sub-models as well as missing climate feedbacks due to a neglect of dynamic vegetation and ice sheet evolution in the model. This motivates the use of isotopic simulations driven by higher levels of GHGs (such as the IPSL_A and HadCM3_B simulations) when attempting to learn about past warm climates.

We show that understanding SST changes is key to understanding warm climate Greenland isotopic changes (Masson-Delmotte et al. 2011; Sime et al. 2013). Indeed, precipitation sourced from local high-latitude regions is enriched in $\delta^{18} \mathrm{O}$. Increasing (decreasing) the proportion of locally sourced precipitation therefore raises (lowers) $\delta^{18} \mathrm{O}$ in Greenland snow. Thus SST changes which drive differences in evaporative sources, strongly affect Greenland $\delta^{18} \mathrm{O}$ values. From the results of the IPSL_A simulation, we observe strong SST increases south of $50^{\circ} \mathrm{N}$ but only small changes around northern Greenland (Fig. 2B). This leads to a higher proportion of distally sourced $\left(\delta^{18} \mathrm{O}\right.$ depleted) Greenland precipitation. The HadCM3_B simulation shows that the northern regions of Greenland experience SST increases of up to $\sim 10^{\circ} \mathrm{C}$ (Fig. $2 \mathrm{C}$ ), associated with reduced sea ice cover (not shown). This leads to substantially more local precipitation and as a result, enriched ice $\delta^{18} \mathrm{O}$.

\section{What can we learn from these re- sults?}

Our simulations provide an insight into how ice core observations could be related to wider climatic changes across the North Atlantic and Arctic Oceans. On one hand, we observe from the HadCM3_B simulation that if the seas to the north of Greenland get warmer and sea ice is reduced, then central Greenland $\delta^{18} \mathrm{O}$ increases of $3 \%$ (Fig. 1C) can be simulated with associated SSTs of around $+4^{\circ} \mathrm{C}$ (Fig. 2C). This pattern of sea surface warming lies within current interglacial observational constraints (McKay et al. 2011; Turney et al. 2010). On the other hand, the IPSL_A simulation shows that if the Arctic SSTs north of Greenland are almost unchanged and SST warming is instead concentrated in the south of Greenland (Fig. $2 \mathrm{~B})$ the $3 \% \circ \delta^{18} \mathrm{O}$ rise requires Greenland surface temperatures to increase by between $\sim 8$ and $14^{\circ} \mathrm{C}$ (Fig. 1B). It also requires an SST change to the southeast of Greenland of more than $\sim 20^{\circ} \mathrm{C}$ (Fig. 2B). Such a large change is very unlikely and this suggests that the warming resulting from the HadCM3_B may be more representative of LIG changes.
To summarize, while during colder than present day climates, Greenland $\delta^{18} \mathrm{O}$ originates from distal precipitation sources (Masson-Delmotte et al. 2005), our new simulations suggest that during warmer climates, Greenland $\delta^{18} \mathrm{O}$ precipitation can originate from local high latitude regions. As a result, we propose that sea surface warming and sea ice loss in regions north of Greenland may have caused much of the observed Greenland $\delta^{18} \mathrm{O}$ rise and also contributed to a central Greenland temperature increase of about $+4^{\circ} \mathrm{C}$ during the LIG. SST reconstructions from marine sediment cores drilled in regions to the north of Greenland would be necessary to test our hypothesis.

\section{Outlook}

Our experiments have shown that improved model parameterizations and/ or coupling with dynamic ice sheet and vegetation models are necessary for investigating Greenland LIG changes forced by more realistic orbital and GHG forcings. Isotope-enabled model simulations, which include dynamic ice sheets, would also be useful for helping us infer LIG ice sheet changes from isotopic observations. Finally, performing atmospheric isotopic model simulations is also beneficial in understanding other ice core tracers used to interpret Greenland moisture source changes (such as the deuterium excess and the recently developed $\delta^{17} \mathrm{O}$ tracer).

\section{Selected references}

Full reference list online under:

http://www.pages-igbp.org/products/newsletters/ref2013_1.pdf

Masson-Delmotte V et al. (2011) Climate of the Past 7, 1041-1059 Masson-Delmotte V et al. (2005) Science 309: 118-121

McKay NP, Overpeck JT, Otto-Bliesner BL (2011) Geophysical Research Letters 38, doi: 10.1029/2011GL048280

NorthGRIP Project members (2004) Nature 431: 47-151

Sime LC et al. (2013) Quaternary Science Reviews 67: 59-80

\section{A IPSL_LIG pattern}

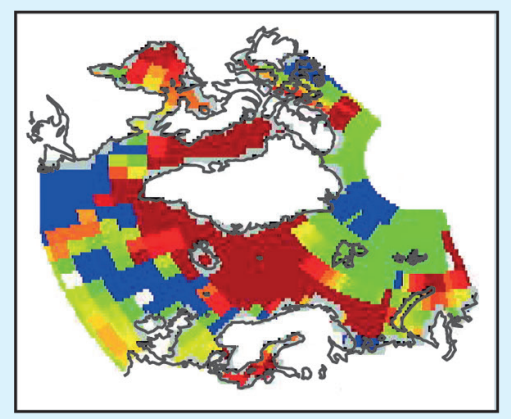

\section{B IPSL_A pattern}

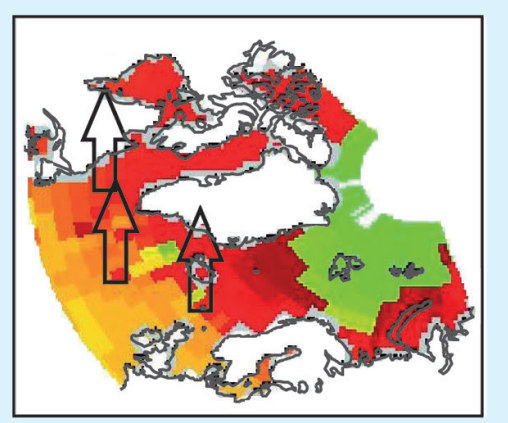

\section{HadCM3 B pattern}

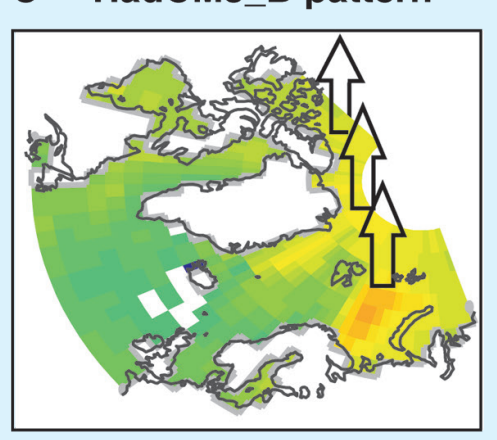

Figure 2: Differences between the control (present day) and warmer simulation SSTs. Scaled (as in Fig. 1). A) IPSL_LIG simulation, (B) IPSL_A simulation and (C) HadCM3_B simulation. The viewpoint in each case is from above Europe, looking across the North Atlantic Ocean, Greenland, and part of the Arctic Ocean. Schematic arrows show the main changes in precipitation (evaporation) sources for Greenland snow. 